\title{
An Unusual Neonatal Presentation of Scimitar Syndrome
}

\author{
Ahmad Abdul Aziz, MD ${ }^{1} \quad$ Sumesh Thomas, MD ${ }^{1} \quad$ David Lautner, MD $\quad$ Essa Hamadan Al Awad, MD \\ 1 Section of Neonatology, Department of Pediatric, University of \\ Calgary, Calgary, Alberta, Canada \\ ${ }^{2}$ Department of Diagnostic Imaging, Foothill Medical Centre, \\ University of Calgary, Calgary, Alberta, Canada \\ Address for correspondence Essa Hamadan Al Awad, MD, Section of \\ Neonatology, University of Calgary, Peter Lougheed Centre, 3500, \\ 26th Ave, NE, Calgary, AB T1Y6J4, Canada \\ (e-mail: essa.alawad@albertahealthservices.ca).
}

Am J Perinatol Rep 2018;8:e138-e141.

Abstract
Keywords
- neonatology
- perinatology
- pediatric cardiology
- pulmonology

Scimitar syndrome is characterized by partial or total anomalous pulmonary venous return from the right lung along with pulmonary hypoplasia. We present a case of a 37 weeks' gestation male infant with antenatal ultrasound findings of suspected partial anomalous pulmonary venous return (PAPVR) and coarctation of the aorta. The newborn presented with respiratory distress, a chest X-ray and chest computed tomography (CT) angiogram confirmed the diagnosis of scimitar syndrome. The combination of scimitar syndrome with aortic coarctation is extremely rare with only a few cases previously reported.

\section{Case History}

A 37 weeks' gestation male infant was born to a 31 years old gravida 2, para 1 mother with a dichorionic diamniotic twin pregnancy. Parents were nonconsanguineous and family history was noncontributory. She had a spontaneous healthy pregnancy with protective antenatal serology. Her Group B streptococcus (GBS) status was unknown and gestational diabetes screen was normal. First trimester screening for trisomy 18,13, and 21 was negative. At 20 weeks' gestation, ultrasound findings were suggestive of partial anomalous pulmonary venous return (PAPVR) and suspected coarctation of aorta for twin A. There was, however, no growth discordance between the twins.

A fetal echocardiogram at 26 weeks and 6 days' gestation age confirmed findings of PAPVR with right inferior pulmonary vein draining into the right atrium, narrowing/hypoplasia of the right branch of pulmonary artery, and a suspicion of coarctation of the aorta. Subsequent ultrasounds confirmed cardiac findings in twin A with growth restriction at 35 weeks' gestation. Both twins had ultrasounds findings of normal amniotic fluid indices and biophysical profiles.

The twins were born at 37 weeks' gestation by cesarean section because of evolving growth discordance. Twin B weighed $3.5 \mathrm{~kg}$ at birth with no respiratory distress and preductal oxygen saturations of $90 \%$ in room air. Twin B remained well to discharge home.

Twin A had a decreased breath sounds in the right hemithorax with an ejection systolic murmur of grade $3 / 6$ intensity heard in the pulmonary area. Heart rate was $160 / \mathrm{min}$ and blood pressure in the right arm was $65 / 40 \mathrm{~mm} \mathrm{Hg}$. Lower limbs were cool to touch with weak femoral and posterior tibial arterial pulsation. Preductal blood pressure measured with right arm: 64/36, mean $48 \mathrm{~mm} \mathrm{Hg}$, while postductal blood pressure measured with right leg: 54/28, mean $37 \mathrm{~mm} \mathrm{Hg}$.

Postnatal echocardiography confirmed coarctation of the isthmus of the aorta, following which a prostaglandin infusion was started. He required a maximum of $1 \mathrm{~L} / \mathrm{min}$ of nasal cannula flow with $25 \%$ fraction of inspired oxygen $\left(\mathrm{FiO}_{2}\right)$ to maintain preductal oxygen saturations greater than $90 \%$. The first chest X-ray ( - Fig. 1) showed atelectasis of the right hemithorax with a mediastinal shift to the right which raised concern of the diagnosis of scimitar syndrome. A chest computed tomography (CT) angiogram performed on day 3 of life showed hypoplastic right lung (-Fig. 2) with only two bronchi, a hypoplastic right pulmonary artery and PAPVR of the right pulmonary vein to the inferior vena cava (IVC) essentially at the level of the atrial-caval junction (-Figs. 3-5). There were no identified systemic collaterals, or evidence of scimitar vein stenosis. Imaging of the lung bases demonstrated no evidence received

February 20, 2018 accepted after revision April 2, 2018
DOI https://doi.org/

10.1055/s-0038-1656533. ISSN 2157-6998.
Copyright $\odot 2018$ by Thieme Medical

Publishers, Inc., 333 Seventh Avenue, New York, NY 10001, USA. Tel: +1(212) 584-4662.
License terms

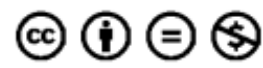




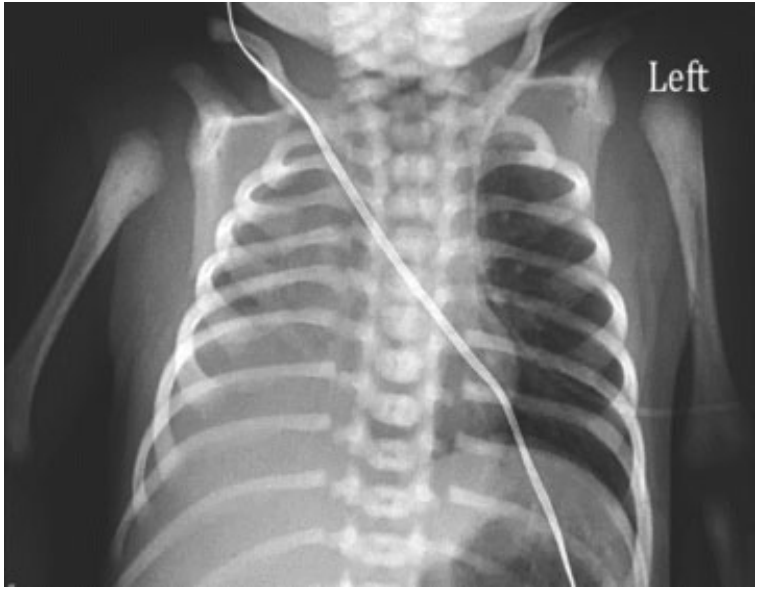

Fig. 1 Anteroposterior (AP) supine chest radiograph: There is abnormal added dense opacity and volume loss in the right hemithorax. The left heart border and cardiac size are normal. There is no focal abnormality of the left lung or bony thorax. Decreased right thoracic loss of volume may suggest hypogenetic lung in a child with known partial anomalous pulmonary venous return (PAPVR).

of a sequestration, but definite leftward herniation of the medial basal right lower lung parenchyma across the midline was present in the central inferior chest anterior to the distal esophagus and descending thoracic aorta, consistent with the presence of a pseudohorseshoe lung malformation ( - Figs. 6 and 7).

A nonstenotic bicuspid aortic valve and coarctation of aorta with hypoplasia of the distal aortic arch were identified. Subsequent echocardiography studies demonstrated increased pulmonary pressure, a large patent ductus arteriosus (PDA) and a small anterior muscular ventricular septal defect (VSD). In our case, the PAPVR anomaly included one of the pulmonary veins draining into the right atrium that was detected antenatally, and another pulmonary vein draining

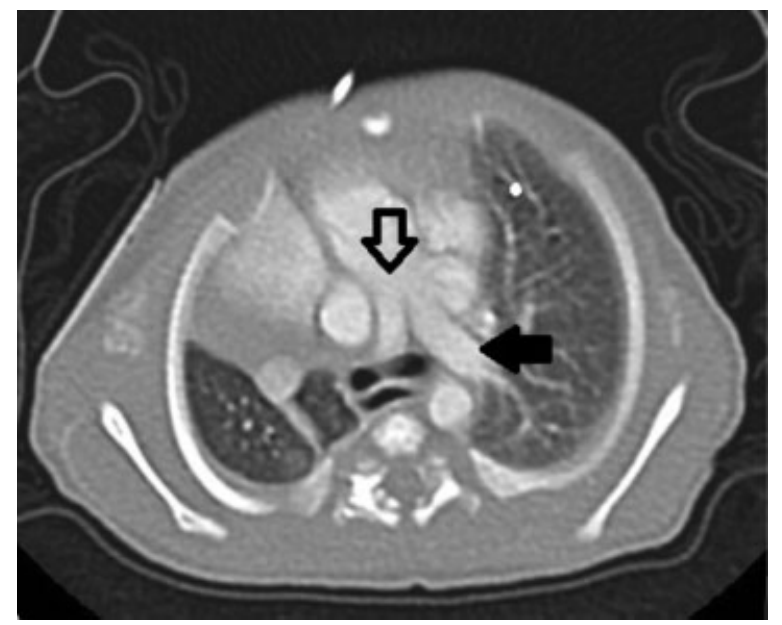

Fig. 2 Axial chest computed tomography (CT) angiogram (lung windows): The right lung is small compared with the normal sized left lung and the mediastinal structures are shifted rightwards due to volume loss in the right thorax. The right pulmonary artery is small/hypoplastic (open arrow) compared with left pulmonary artery (black arrow).

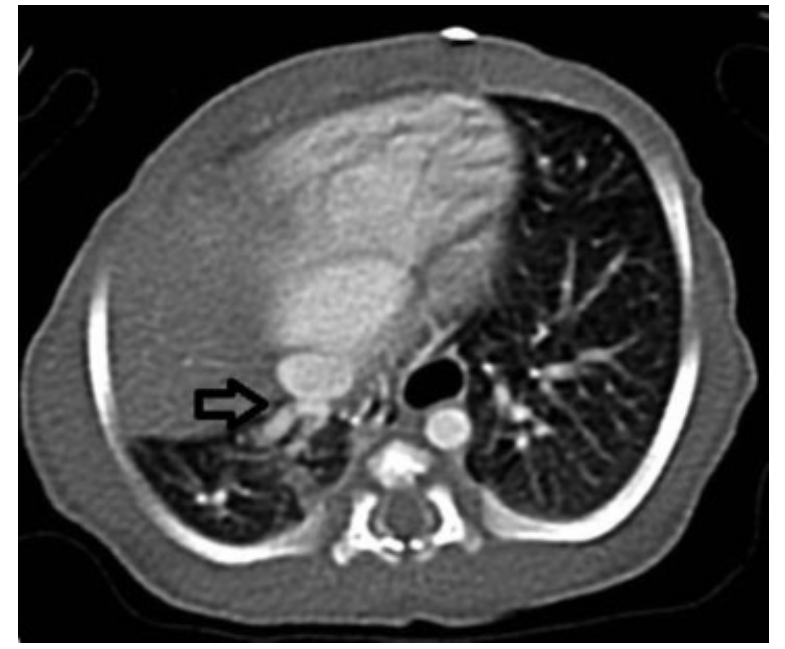

Fig. 3 Axial image from contrast-enhanced computed tomography (CT) chest (lung windows) showing small right lower lung and anomalous pulmonary venous drainage (scimitar vein) draining into the posterior inferior vena cava (IVC) near the level of the junction with the right atrium.

to the IVC at the level of the atrial-caval junction, as per the chest $\mathrm{CT}$ angiogram findings.

He had surgical repair of the aortic coarctation by subclavian arterial flap repair on day 16 of age. Pulmonary hypertension improved on sildenafil following successful postoperative extubation.

\section{Discussion}

Scimitar syndrome was first described in 1836 by George Cooper during the autopsy of a 10-month-old infant. The

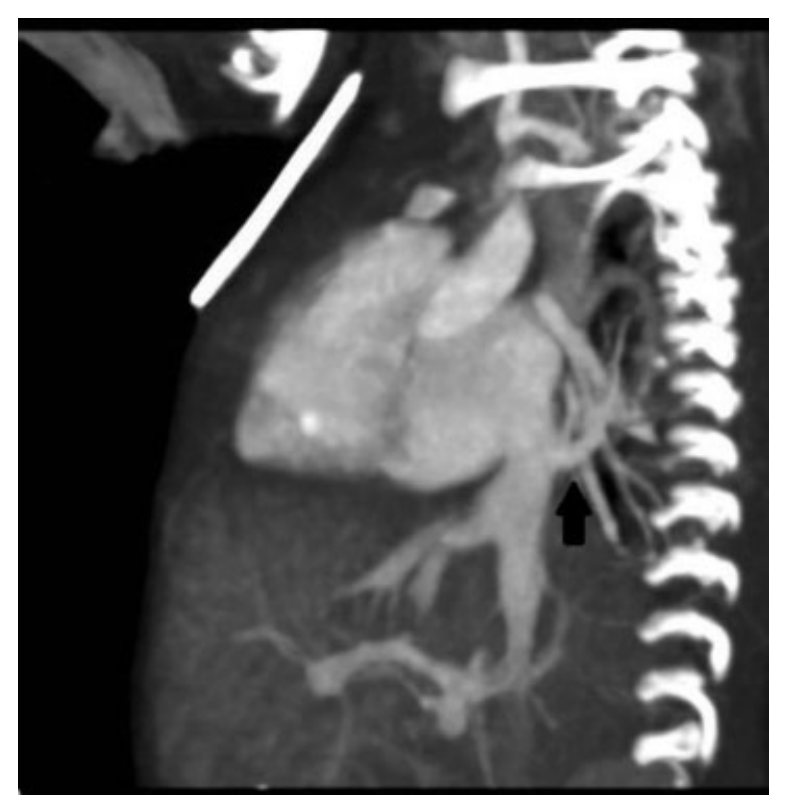

Fig. 4 Maximum intensity projection (MIP) sagittal reformatted contrast-enhanced computed tomography (CT) image demonstrates abnormal obliquely and vertically oriented draining vein from the right lower lobe entering the posterior aspect of inferior vena cava (IVC) at its junction with the right atrium. 


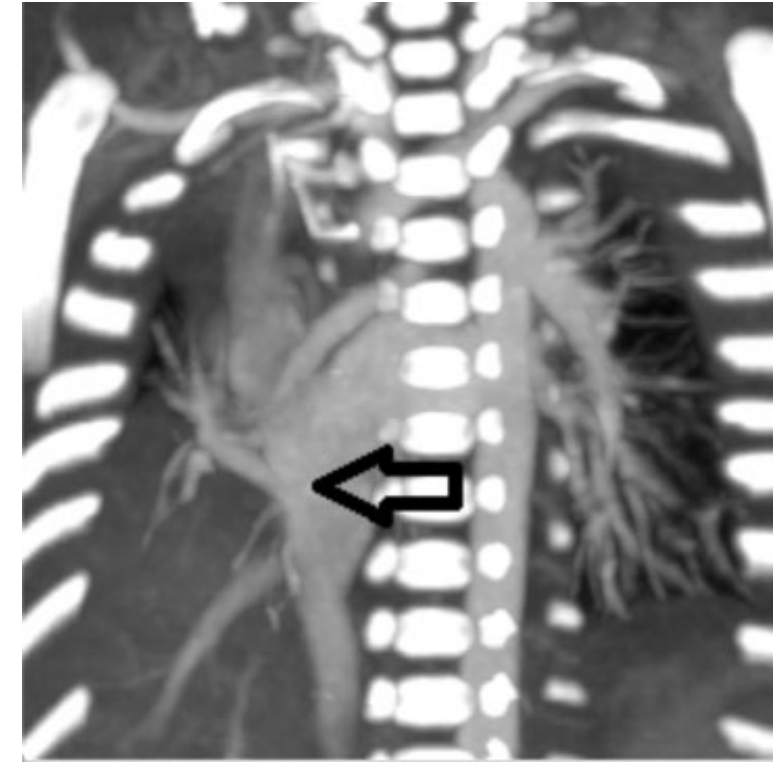

Fig. 5 Maximum intensity projection (MIP) coronal reformatted contrast-enhanced computed tomography (CT) image demonstrates abnormal pulmonary venous drainage. The right inferior pulmonary vein is joining the posterolateral aspect of the right atrium/superior vena cava (RA/SVC) junction.

incidence of scimitar syndrome is estimated at 1 to $3 /$ 100,000 live births. ${ }^{1,2}$ However, its true incidence may be much higher as some of those affected may be asymptomatic.

The diagnosis is made by echocardiography, characteristic chest X-ray findings, and confirmatory CT chest findings. CT chest angiography provides excellent visualization of the vascular anatomy of this complex congenital defect noninvasively. ${ }^{3}$

Scimitar syndrome is a rare association of congenital cardiopulmonary anomalies characterized by anomalous pulmonary veins (scimitar vein) that drains into the IVC, a hypoplastic right lung, and dextroposition of the heart. It has been reported in 3 to $6 \%$ of patients with partial anomalous pulmonary venous connection. Patients are either diagnosed

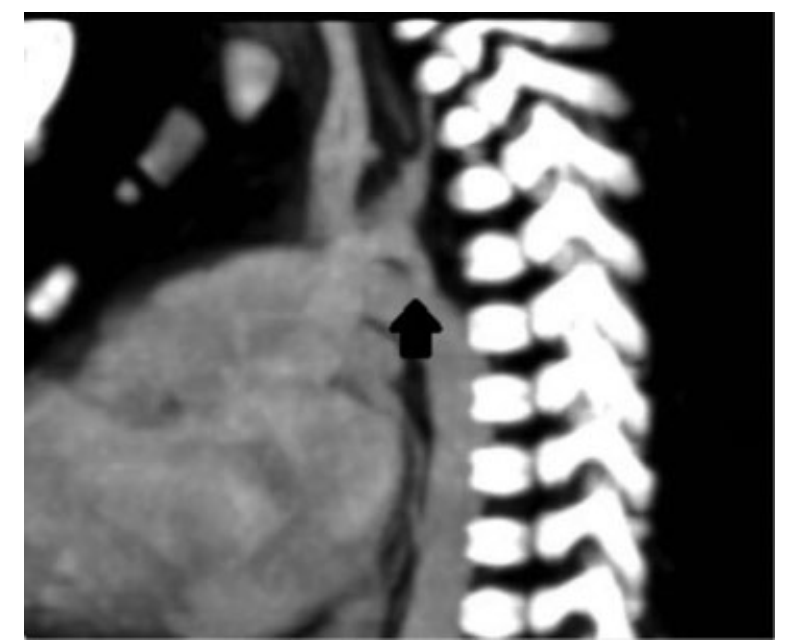

Fig. 6 Contrast-enhanced computed tomography (CT) chest maximum intensity projection (MIP) sagittal reformatted image demonstrating coarctation of the distal transverse aorta at the isthmus (black arrow).

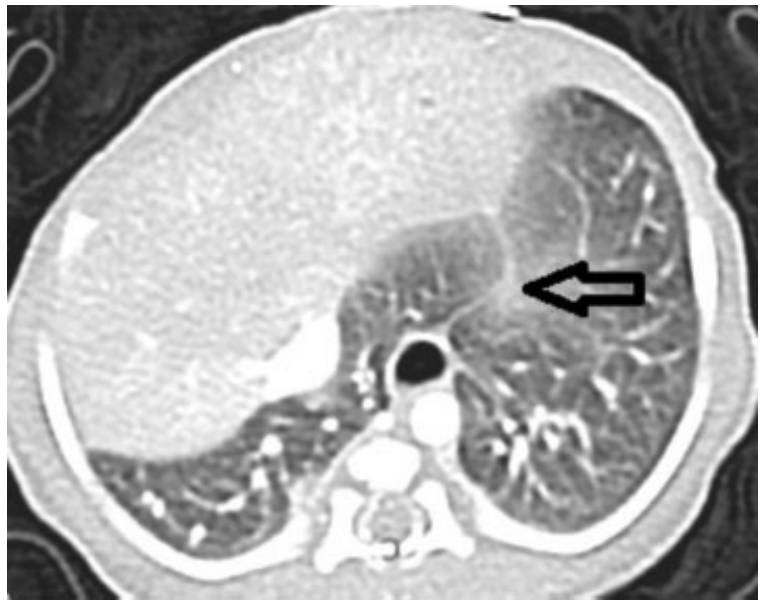

Fig. 7 Axial image from contrast-enhanced computed tomography (CT) chest (lung windows) showing bulging pulmonary parenchyma (isthmus) from the medial right lung base crossing the midline with adjacent enveloping pleural reflection or pseudohorseshoe lung (open arrow). No abnormal contralateral bronchi or pulmonary arterial branches were detected.

early with severe symptoms (infantile type) or late with minimal symptoms (childhood/adult type). ${ }^{4,5}$

Schramel et al recognized two different types of scimitar veins: type 1 is simple classic vein that runs from the middle of the right lung to the cardiophrenic angle and type 2 is double arched vein in the upper and lower lung zones, with drainage into the left atrium and inferior caval vein., ${ }^{4,5}$

The presentation of the syndrome could be as early as immediately after birth, and the diagnosis should be suspected when the signs of respiratory distress and/or heart failure are present in association with radiological findings of cardiac dextroposition and haziness or suspicion of atelectasis of the right lung. ${ }^{6}$

Scimitar syndrome often presents as an isolated finding with a benign outcome; however, when associated with other cardiac defects and pulmonary arterial hypertension, there is an increased risk of congestive heart failure and mortality. The etiology of pulmonary hypertension in infants with scimitar syndrome is variable and may be related to a decreased rightsided pulmonary vascular bed, scimitar vein stenosis, and unappreciated systemic collateral blood flow along with intracardiac shunts, or additional comorbidities, such as developmental lung disease. Horseshoe lung is a rare pulmonary malformation associated with scimitar syndrome. Eighty percent of reported cases occur in patients with congenital pulmonary venolobar (scimitar) syndrome. ${ }^{7}$ Typical features of horseshoe lung include an isthmus of the pulmonary parenchymal tissue arising from the right lung base, bridging the right and left lungs, which resides posterior to the inferior aspect of the middle mediastinum. Pulmonary arterial and bronchial supply extend from the right lower lobe pulmonary artery and bronchus. It has been suggested that when the isthmus is completely encased in a pleural membrane, as it was in our patient, this be termed pseudohorseshoe lung. ${ }^{8}$

Pulmonary hypertension is a problem seen in infants and older children with scimitar syndrome. ${ }^{9}$ The age of presentation 
Table 1 Review of literature of published cases with scimitar syndrome that associated with aortic arch abnormalities

\begin{tabular}{|l|l|l|l|l|}
\hline Author & Year & $\begin{array}{l}\text { Number } \\
\text { of cases }\end{array}$ & Cardiac anomaly & Outcome \\
\hline $\begin{array}{l}\text { Gikonyo } \\
\text { et al }^{14}\end{array}$ & 1986 & 2 & $\begin{array}{l}\text { Case \#1: Bicuspid aortic valve, tubular hypo- } \\
\text { plasia of aortic arch, ASD, VSD, PDA. Persis- } \\
\text { tent left superior vena cava to coronary sinus }\end{array}$ & $\begin{array}{l}\text { Died at the age of } 7 \text { d in a state of congestive } \\
\text { failure following right } \\
\text { ventricular angiography }\end{array}$ \\
\hline $\begin{array}{l}\text { Oshima } \\
\text { et al }\end{array}$ & 2003 & 1 & $\begin{array}{l}\text { Case \# 2: } \\
\text { Tubular hypoplasia of aortic arch, VSD, PDA, } \\
\text { anomalous venous drainage }\end{array}$ & $\begin{array}{l}\text { Experienced intraoperative cardiac arrest, } \\
\text { and resuscitation was unsuccessful }\end{array}$ \\
\hline $\begin{array}{l}\text { Marcondes } \\
\text { et al }{ }^{15}\end{array}$ & 2014 & 1 & $\begin{array}{l}\text { Coarctation of aorta, extremely hypoplastic } \\
\text { right pulmonary artery and right lung, pul- } \\
\text { monary sequestration, and ASD }\end{array}$ & $\begin{array}{l}\text { At 35 d of life, patient underwent successful } \\
\text { repair of coarctation and PAPVR }\end{array}$ \\
\hline $\begin{array}{l}\text { Rezaei } \\
\text { et al }{ }^{16}\end{array}$ & 2016 & 1 & $\begin{array}{l}\text { Aoortic arch hypoplasia, no coarctation, hypoplastic right pulmonary artery. } \\
\text { descending aorta }\end{array}$ & $\begin{array}{l}\text { At 7 wk of life patient underwent successful } \\
\text { surgical repair }\end{array}$ \\
\hline
\end{tabular}

Abbreviations: ASD, atrial septal defect; PAPVR, partial anomalous pulmonary venous return; PDA, patent ductus arteriosus; VSD, ventricular septal defect.

and the presence of associated anomalies are important in predicting the outcome. In general, presentation in infancy and presence of heart failure are poor prognostic factors.

The combination of scimitar syndrome with aortic coarctation is rare, with only few cases reported. ${ }^{10-12}$ The literature describes the correction of associated cardiac defects with the therapeutic occlusion of anomalous arterial supply to the affected lung can led to benign outcomes comparable to that in primarily isolated forms. ${ }^{13}$

We did a review of literature of published cases with scimitar syndrome that associated with aortic arch abnormalities (-Table 1).

\section{Conclusion}

Although scimitar syndrome has been described in the literature, it is rare and variable in its presentation, especially in the neonatal period. This diagnosis should be considered when right-sided "atelectasis" does not improve or when dextroposition of the heart is associated with right lung hypoplasia. Scimitar syndrome can be associated with cardiac anomalies but only few cases are reported with aortic coarctation. Our case report highlights this rare combination.

\section{Conflict of Interest}

None.

\section{References}

1 Midyat L, Demir E, Aşkin M, et al. Eponym. Scimitar syndrome. Eur J Pediatr 2010;169(10):1171-1177

2 Juraszek AL, Cohn H, Van Praagh R, Van Praagh S. Isolated leftsided scimitar vein connecting all left pulmonary veins to the right inferior vena cava. Pediatr Cardiol 2005;26(06):846-847

3 Sinha R, Singh P, Bhatnagar AK, Batra A. Scimitar syndrome: imaging by magnetic resonance angiography and Doppler echocardiography. Indian J Chest Dis Allied Sci 2004;46(04):283-286
4 Ciçek S, Arslan AH, Ugurlucan M, Yildiz Y, Ay S. Scimitar syndrome: the curved Turkish sabre. Semin Thorac Cardiovasc Surg Pediatr Card Surg Annu 2014;17(01):56-61

5 Schramel FM, Westermann CJ, Knaepen PJ, van den Bosch JM. The scimitar syndrome: clinical spectrum and surgical treatment. Eur Respir J 1995;8(02):196-201

6 Al Rukban H, Al Ghaihab M, Tamimi O, Al-Saleh S. Clinical spectrum of infantile scimitar syndrome: a tertiary center experience. Ann Pediatr Cardiol 2014;7(01):29-33

7 Frank JL, Poole CA, Rosas G. Horseshoe lung: clinical, pathologic, and radiologic features and a new plain film finding. AJR Am J Roentgenol 1986;146(02):217-226

8 Tosun A, Leblebisatan S. Congenital pseudohorseshoe lung associated with scimitar syndrome. Iran J Radiol 2012;9(02):99-102

9 Gupta ML, Bagarhatta R, Sinha J. Scimitar syndrome: a rare disease with unusual presentation. Lung India 2009;26(01):26-29

10 Vida VL, Padrini M, Boccuzzo G, et al; Italian Society of Pediatric Cardiology. Natural history and clinical outcome of "uncorrected" scimitar syndrome patients: a multicenter study of the Italian society of pediatric cardiology. Rev Esp Cardiol (Engl Ed) 2013;66 (07):556-560

11 Espinola-Zavaleta N, Játiva-Chávez S, Muñoz-Castellanos L, ZamoraGonzález C. Clinical and echocardiographic characteristics of scimitar syndrome [in Spanish]. Rev Esp Cardiol 2006;59(03):284-288

12 Oshima Y, Hashimoto I, Shimazu C, Ichida F. Atypical infantile form of scimitar syndrome with bronchomalacia. Interact Cardiovasc Thorac Surg 2003;2(03):298-300

13 Glancy DL, Braunwald NS, O'Brien KP, Roberts WC. Scimitar syndrome associated with patent ductus arteriosus, aortic coarctation and irreversible pulmonary hypertension. Johns Hopkins Med J 1968;123(06):297-304

14 Gikonyo DK, Tandon R, Lucas RV Jr, Edwards JE. Scimitar syndrome in neonates: report of four cases and review of the literature. Pediatr Cardiol 1986;6(04):193-197

15 Marcondes LDF, Ghez O, Magee AG. Scimitar syndrome and anomalous origin of the circumflex artery from the main pulmonary artery in infancy: a case report. Cardiol Young 2014;28 (06):791-794

16 Rezaei M, Borghei A, Farahbakhsh N, Amoozgar H. A Neonate with scimitar syndrome, absent right pulmonary artery, imperforated anus, and coarctation of the aorta. Int Cardiovasc Res J 2016;10 (04):202-204 